\title{
Intracerebroventricular injection of orexin-A, but not orexin-B, induces arousal of layer-type neonatal chicks
}

\author{
Katayama, Sachiko \\ Laboratory of Regulation in Metabolism and Behavior, Graduate School of Bioresource and \\ Bioenvironmental Sciences, Kyushu University
}

\section{Hamasu, Kousuke}

Laboratory of Regulation in Metabolism and Behavior, Graduate School of Bioresource and Bioenvironmental Sciences, Kyushu University

\section{Shigemi, Kazutaka}

Laboratory of Regulation in Metabolism and Behavior, Graduate School of Bioresource and Bioenvironmental Sciences, Kyushu University

Cline, Mark A.

Department of Biology, Radford University | Laboratory of Regulation in Metabolism and Behavior, Graduate School of Bioresource and Bioenvironmental Sciences, Kyushu University I Laboratory of Regulation in Metabolism and Behavior, Graduate School of Bioresource and Bioenvironmental Sciences, Kyushu University

他

http://hdl. handle. net/2324/26043

出版情報 : Comparative Biochemistry and Physiology Part A : Molecular \& Integrative Physiology. 157 (2), pp.132-135, 2010-10. Elsevier

バージョン:

権利関係: (C) 2010 Elsevier Inc. 


\section{Intracerebroventricular injection of orexin-A, but not orexin-B, induces arousal of layer-type neonatal chicks}

S. KATAYAMA, K. HAMASU, K. SHIGEMI, M. A. CLINE ${ }^{1}$,AND M. FURUSE*

Laboratory of Regulation in Metabolism and Behavior, Graduate School of Bioresource and Bioenvironmental Sciences, Kyushu University, Fukuoka 812-8581, Japan

${ }^{1}$ Department of Biology, PO Box 6931, Radford University, Radford, Virginia, 24142,

United States

Short version of the title: OREXINS AND AROUSAL OF CHICKS

*Correspondence to: M. Furuse, PhD, Laboratory of Regulation in Metabolism and Behavior, Graduate School of Bioresources and Bioenvironmental Sciences, Kyushu University, Fukuoka 812-8581, Japan.

E-mail address: furuse@ @rs.kyushu-u.ac.jp

Phone \& Fax: +81-92-642-2953 


\begin{abstract}
In order to determine if orexins affect arousal in neonatal chicks, we intracerebroventricularly (ICV) injected either orexin-A or orexin-B to layer and broiler type chicks and measured their behaviors and food intake following injection. Layer chicks treated with orexin-A at 0.2 and $2.0 \mathrm{nmol}$ had increased arousal but their food intake was not affected. However, arousal was not affected in broiler chicks treated with orexin-A, but they spent less time feeding. When orexin-B was administered to layer and broiler chicks, neither had altered arousal and their food intake was not affected. Therefore, the orexin peptides may differentially affect arousal in the two stocks tested; orexin-A causes a stock dependant increase whereas orexin-B does not affect either.
\end{abstract}

Key words : arousal, broiler, layer, neonatal chicks, orexin 


\section{Introduction}

Orexins were first identified as neurotransmitters through reverse-pharmacology while searching for ligands of previously orphan receptors, now called orexin receptor-1 OX1R and receptor-2 OXR2 (Sakurai et al., 1998). Sakurai et al. (1998) identified orexin-A and orexin-B as ligands of OX1R and OXR2, both of which are G-protein-coupled receptors that are expressed in the hypothalamus. The amino acid sequences of orexin-A and orexin-B originate from a common precursor, preproorexin. Around the same time, another group also identified orexin-A and orexin-B but called them hypocretin-1 and hypocretin-2, respectively (from the brain sites where they were isolated; de Lecca et al., 1998), hence their alternative names. The orexins are most noted for their role in wakefulness; central injection of orexin induces arousal and activity and decreases non REM and REM sleep (Hagan et al., 1999). They are thought to be important mediators of sleep/wake cycles.

Orexins are secondarily known for their affect on appetite; their effects on feeding behavior in neonatal broiler chicks were first documented by Furuse et al. (1999). Although under ad lib feeding, human orexin-A did not cause an effect, human orexin-B caused decreased food intake in broiler chicks. This anorexigenic effect was not observed in a second experiment when a $3 \mathrm{~h}$ fast preceded injection of orexin-B. This is unusual as fasting usually increases the differential feeding responses of control and anorexigenic peptide treatment groups of chicks. Thus, the appetite-associated response of orexin-B in broilers appears dependent on feeding state. Other groups report that the effects of orexins are dependent on time of day; administration in the early light phase increases food intake in fed rats, but if injected in the middle of the dark phase has no effect (Sakurai et al., 1998, Yamanaka et al., 2000). Adiposity also seems to play a role in how the orexins affect appetite regulation; selectively-bred obesity-resistant rats had increased spontaneous physical activity as compared to those with diet-induced obesity after orexin-A injection (Teske 
et al., 2006). Findings by these groups as a whole demonstrate the complexities of the physiological pathways to orexin-B induced anorexia; a plethora of environmental and physiological factors influence how organisms respond.

With respect to chickens, layers are lean compared to broilers (Zhao et al., 2004). Therefore, testing orexins in layers vs. broilers may provide insight into adiposity's effect on the orexin system in birds. To our knowledge no such reports exist. Sleep and physical activity are also affected by orexins. Broiler and layer stocks also have different sleep patterns; broiler chicks sleep longer than layers under continuous lighting (Saito et al., 2003) and also differ in their physical activity (Siegel et al., 1989).

Thus, the purpose of the present study was firstly to examine the effects of orexins on feeding behavior and sleep/arousal cycle of layer and broiler stocks, and secondly to determine if orexin-A and orexin-B caused differential effects between the two stocks.

\section{MATERIALS AND METHODS}

\subsection{Animals}

Day-old male layer chicks (Julia) were purchased from a local hatchery (Gen Corporation, Gifu, Japan). Fertilized broiler eggs (Chunky) were purchased from local hatchery (Mori Hatchery, Fukuoka, Japan), and then incubated at $37.5^{\circ} \mathrm{C}$ until one day post hatch. The chicks were maintained in a windowless room at $30 \pm 1^{\circ} \mathrm{C}$ with $24 \mathrm{~h}$ lighting. They were given free access to a commercial starter diet (Toyohashi Feed and Mills Co. Ltd., Aichi, Japan) and tap water unless otherwise noted. When they were divided into treatment groups, body weights were distributed as uniformly as possible. Experimental procedures followed the guidance for Animal Experiments in Faculty of Agriculture and in the Graduate Course of Kyushu University and the Law (No. 105) and Notification (No. 6) of the Japanese 
Government.

\subsection{Peptide preparation}

Chicks were intracerebroventricularly (ICV) injected with $10 \mu \mathrm{l}$ of peptide dissolved in $0.85 \%$ saline containing $0.1 \%$ Evans blue as a vehicle using a microsyringe according to the methods of Davis et al. (1978). Orexin-A (human, rat, mouse and bovine) and orexin-B (human) were purchased from Peptide Institute (Osaka, Japan). After data collection, chicks were euthanized and brains were sectioned coronally to verify injection site location; any chick without dye present in the lateral ventricle system was removed from the statistical analysis.

\subsection{Behavioral observation}

Chicks were transferred from a group cage to individual transparent acrylic cages allowing auditory but not visual contact with one another $1 \mathrm{~d}$ before the experiment. On the day of the experiment, layer chicks 4-5 d post hatch and broilers 3-4 d post hatch were ICV injected with either 0 (vehicle), 0.2 , or $2.0 \mathrm{nmol}$ of orexin-A or orexin-B. Immediately following injection, chicks were placed back into their individual cages and were digitally (SELCO Corporation, Kyoto, Japan) recorded for 60 mins. Food intake during the 60 min observation period was measured at the end of observation. After data collection, digital video recordings were reviewed and behaviors were categorized into 4 mutually exclusive categories: (1) standing with eyes opened (active wakefulness), (2) standing with eyes closed, (3) sitting with eyes open, and (4) sitting with eyes closed (sleep-like posture), according to the report of van Luijtelaar et al. (1987). The amount of time spent performing each behavior was observed and recorded. Active wakefulness was further categorized as either with or without feeding behavior according to Takagi et al. (2001). 


\subsection{Statistical analysis}

The amount of time spent in each behavior and food intake were analyzed by one-way analysis of variance (ANOVA) followed by Tukey-Kramer test as a post hoc. Significant differences implied a P value of less than 0.05 . Statistical analysis was conducted using the commercially available package, StatView (version 5, SAS Institute, Cary, USA, 1998).

\section{RESULTS}

In layer chicks, both orexin-A-injected groups spent significantly more time in active wakefulness $[\mathrm{F}(2,18)=17.887, \mathrm{P}<0.0001]$ and spent significantly less time in sleep-like posture $[\mathrm{F}(2,18)=21.940, \mathrm{P}<0.0001]$ than did their respective control groups (Table 1). However, food intake (control; $0.54 \pm 0.163 \mathrm{~g}, 0.2 \mathrm{nmol} ; 0.498 \pm 0.205 \mathrm{~g}$, and $2.0 \mathrm{nmol}, 0.677 \pm 0.163 \mathrm{~g}$ ) and time spent feeding (Table 1) were not significantly affected in either stock. As shown in Table 2, there were no significant differences between the orexin-B groups and the control group for neither behavior nor feeding in layer chicks. Food intake (control; $0.844 \pm 0.235 \mathrm{~g}, 0.2 \mathrm{nmol} ; 0.613 \pm 0.210 \mathrm{~g}$, and $2.0 \mathrm{nmol}, 0.458 \pm 0.130 \mathrm{~g}$ ) was not affected. Table 3 shows the effects of ICV orexin-A on broiler chicks; no significant differences between orexin-A groups and the control group were detected except for feeding time, which was significantly reduced at a similar magnitude for both orexin-A treatments. The orexin-A treated group spent less time feeding $[\mathrm{F}(2,19)=13.610, \mathrm{P}=0.0002]$ but did not have altered food intake (control; $0.673 \pm 0.037 \mathrm{~g}, 0.2 \mathrm{nmol} ; 0.634 \pm 0.180 \mathrm{~g}$, and $2.0 \mathrm{nmol}, 0.528 \pm$ $0.143 \mathrm{~g})[\mathrm{F}(2,19)=0.315, \mathrm{P}=0.7339]$ compared to controls. Table 4 shows the effects of ICV orexin-B on broiler chicks. No significant differences were found in any parameters between orexin-B and control groups. Food intake was also not affected by orexin-B in broiler chicks (control; $0.717 \pm 0.295 \mathrm{~g}, 0.2 \mathrm{nmol} ; 0.400 \pm 0.194 \mathrm{~g}$, and $2.0 \mathrm{nmol}, 0.272 \pm 0.129 \mathrm{~g}$ ). 


\section{DISCUSSION}

The most dramatic result observed in the present study was the arousal-inducing effect of orexin-A on layer chicks (Table 1). Thus it is not surprising that the time spent sitting with eyes closed (sleeping-like posture) was concurrently significantly decreased by orexin-A treatment. Therefore, orexin-A seems to have an arousal-inducing effect in layer chicks that may be competitive with sleeping. This finding is consistent with previous reports in rodents (Piper et al., 2000, Sakurai et al., 1998, reviewed by Willie et al., 2001) and birds (da Silva et al., 2008). In the present study, orexin-A treated layer chicks were more vocal, actively moved about and sometimes jumped during observation. This may be due to orexin-A induced locomotor activity as seen in rodents (Thorpe et al., 2005). Although locomotion was not directly measured in the present study, the time spent actively moving was significantly increased without a significant difference in a simple arousal state (standing/sitting motionless with eyes open, Table 1). That time spent in sleeping posture was concurrently decreased may suggest that active wakefulness is due to the chicks being awoken. However, Kotz (2006) suggested that the activating and arousal effects of orexin-A were separated in rodents. This is not clear in the case of layer chicks. Yamanaka et al. (2003) suggested that orexins were effective when animals were searching for food, but this cannot be applied to birds including chicks in which orexin did not show orexigenic effects. The active wakefulness time (total) of control group in Table 1 was short as compared with that of other control groups in Tables 2-4. We have already observed similar patterns in Table 1 in the previous studies (Kurauchi et al., 2009). The reason was unclear, but we confirmed the effect of orexin-A in layer chicks in another experiment using $0.2 \mathrm{nmol}$ of orexin- $\mathrm{A}$. The values (in second) obtained were: total active wakefulness (control: $1560 \pm 438$ and orexin-A: 2160 \pm 208 ), feeding behavior (control: $439 \pm 124$ and orexin-A: $120 \pm 45$ ), 
without feeding behavior (control: $1121 \pm 315$ and orexin-A: $2041 \pm 170$ ), standing/sitting motionless with eyes open (control: $1235 \pm 290$ and orexin-A: 1440 \pm 208 ), standing motionless with eyes closed (control: $13 \pm 13$ and orexin-A: 0 ) and sitting motionless with eyes closed (control: $791 \pm 204$ and orexin-A: 0 ). The values for without feeding behavior $(\mathrm{P}<0.05)$ and sitting motionless with eyes closed $(\mathrm{P}<0.01)$ were statistically significant by Mann-Whitney $U$ test. Taken together the findings, it is likely that orexin-A increased arousal in layer chicks.

In contrast, orexin-A did not increase arousal in broiler chicks (Table 3). There were no significant changes in time spent in either active wakefulness or sleeping posture. However, time spent feeding was significantly decreased by injection of orexin-A, with no change in food intake, consistent with previous findings in chicks (Furuse et al., 1999). This may be interpreted as orexin-A increases feeding efficiency (g eaten/pecking) in broiler chicks.

Despite the differenential responses of layers and broiler to orexins, there were some similarities. Within $1 \mathrm{~h}$ after injection neither stock had altered food intake for either type of orexin, consistent with the findings of Furuse et al. (1999). This is inconsistent with rodent reports where orexins cause increased food intake within $1 \mathrm{~h}$ post injection (Sakurai et al., 1998). Another similarity between layer and broiler chicks is that in both stocks orexin-B had no significant effects on behaviors (Tables 2 and 4). This is consistent with similar findings in rodents (Willie et al., 2001). On the other hand, the structure of orexin peptides is highly conserved between different mammalian species (Sakurai et al., 1998). According to Ohkubo et al. (2002), chicken orexin-A and orexin-B showed approximately $85 \%$ and $65 \%$ similarities with the corresponding mammalian sequence at the amino acid level. In the present study, we applied mammalian orexin-A and orexin-B. Mammalian orexin-B may not act in the chicken brain.

The differential responses from the two types of orexins used in the present 
study might be due to differences in their receptors. Orexin- $\mathrm{A}$ is a ligand of both OX1R and OX2R while orexin-B activates only OX2R; OX1R is associated with the Gq subclass of $\mathrm{G}$ proteins, and $\mathrm{OX} 2 \mathrm{R}$ is likely associated with the Gq and Gi/o (reviewed in Willie et al., 2001). In the chick brain, mRNA and immunoreactivity for the OX2R receptor were detected, but those of OX1R have yet to be detected (Ohkubo et al., 2003). In rats, orexin-A is associated with resistance to metabolism (Willie et al., 2001). If the physiological characteristics of this receptor are similar to rodents, orexin-B should have had some effect on chick behaviors even though these were weaker than orexin-A. However, orexin-B did not significantly affect any behaviors in either stock at either treatment. Further studies are required to clarify this discrepancy.

Between layer and broiler stocks, orexin synthesis by mRNA expression was not different (Yuan et al., 2009). Layer and broilers consume inherently different amounts of food and hence have different body weights. Therefore, broilers grow at a faster rate and have more adipose tissue than do layers. Orexins are thought to be involved in obesity mechanisms (Tsujino and Sakurai, 2009). OX2R mRNA expression is decreased in obese animals (Yamamoto et al., 2002), and orexin-induced locomotor activity is mediated through OX1R in obesity-prone rats (Teske et al., 2006). That broilers have more adipose tissue than layers supports the hypothesis that orexin receptor expressions are different between the two stocks. From the results of the present study, we cannot clarify mechanisms involved in arousal associated with orexin-A, but the differential responses noted here may be partly explained by layers sleeping less than broilers (Saito et al., 2003). Further studies are required to clarify the central mechanisms of orexin-A in neonatal chicks. To examine the involvement of OX1R in ORX-A-induced action, whether ORX-A-induced action was blocked or not by treatment with the OXR1-selective antagonist, SB-334867, would be investigated in the future. 
In sum, we have demonstrated that arousal is differentially affected by the orexin peptides; orexin-A causes a stock dependant increase whereas orexin-B does not affect either stock. 


\section{References}

Davis, J.L., Masuoka, D.T., Gerbrandt, L.K., Cherkin, A. (1978) Autoradiographic distribution of L-Proline in chicks after intracerebral injection. Physiol. Behav., 22: 693-695.

Furuse, M., Ando, R., Bungo, T., Shimojo, M., Masuda, Y. (1999) Intracerebroventricular injection of orexins does not stimulate food intake in neonatal chicks. Br. Poult. Sci., 40: 698-700.

Hagan, J.J., Leslie, R.A., Patel, S., Evans, M.L., Wattam, T.A., Holmes, S., Benham, C.D., Taylor, S.G., Routledge, C., Hemmati, P., Munton, R.P., Ashmeade, T.E., Shah, A.S., Hatcher, J.P., Hatcher, P.D., Jones, D.N., Smith, M.I., Piper, D.C., Hunter, A.J., Porter, R.A., Upton, N. (1999) Orexin-A activates locus coeruleus cell firing and increases arousal in the rat. Proc. Natl. Acad. Sci. USA, 96: 10911-10916.

Kotz, C.M. (2006) Integration of feeding and spontaneous physical activity: role for orexin. Physiol. Behav., 88: 294-301.

Kurauchi, I., Shigemi, K., Yamada, S., Aoki, M., Kawada, Y., Morishita, K., Denbow, D.M., Furuse, M. (2009) Comparison of central effects of L-ornithine metabolites on stress responses of neonatal chicks. J. Anim. Vet. Adv., 8: 2580-2584.

de Lecca, L., Kilduff, T.S., Peyron, C., Gao, X., Foye, P.E., Danielson, P.E., Fukuhara, C., Battenberg, E.L., Gautvik, V.T., Bartlett, F.S. Ii, Frankel, W.N., van den Pol, A.N., Bloom, F.E., Gautvik, K.M., Sutcliffe, J.G. (1998) The hypocretins: hypothalamus-specific peptides with neuroexcitatory activity. Proc. Natl. Acad. Sci. USA, 95: 322-327.

van Luijtelaar, E.L.J.M., Van Der Grinten, C.P.M., Blokhuis, H.J., Coenen, A.M.L. (1987) Sleep in the domestic hen (Gallus domestics). Physiol. Behav., 41: 
409-414.

Ohkubo, T., Boswell, T., Lumineau, S. (2002) Molecular cloning of chicken prepro-orexin cDNA and preferential expression in the chicken hypothalamus. Biochim. Biophys. Acta, 1577:476-480.

Ohkubo, T., Tsukada, A. \& Shamoto, K. (2003) cDNA cloning of chicken orexin receptor and tissue distribution: sexually dimorphic expression in chicken gonads. J. Mol. Endocrinol., 31: 499-508.

Saito, S., Takagi, T., Koutoku, T., Denbow, D.M., Furuse, M. (2003) Feeding condition and strain differenced influence sleeping behavior in newborn chicks. J. Poult. Sci., 40: 62-68.

Sakurai, T., Amemiya, A., Ishii, M., Matsuzaki, I., Chemilli, R.M., Tanaka, H., Williams, S.C., Richardson, J.M., Kozlowski, G.P., Wilson, S., Arch, J.R.S., Buckingham, R.E., Haynes, A.C., Carr, S.A., Annan, R.S., Mcnulty, D.E., Liu, W-S., Terrett, J.A., Elschourbagy, N.A., Bergsma, D.J., Yanagisawa, M. (1998) Orexins and orexin receptors: a family of hypothalamic neuropeptides and G protein-coupled receptors that regulate feeding behavior. Cell, 92: 573-585.

Siegel, P.B. (1989) The genetic-behavior interface and well-being of poultry. Br. Poult. Sci., 30: 3-13.

da Silva, E.S., Dos Santos, T.V., Hoeller, A.A., Dos Santos, T.S., Pereira, G.V., Menegheli, C., Pezlin, A.I., Dos Santos, M.M., Faria, M.S., Paschoalimi, M.A., Marino-Neto, J. (2008) Behavioral and metabolic effects of central injections of orexins/hypocretins in pigeons (Columba livia). Regul. Pept., 147: 9-18.

Takagi, T., Ando, R., Ohgushi, A., Yamashita, T., Dobashi, E., Hussain-Yusuf, H., Onodera, R., Bungo, T., Sato, H., Furuse, M. (2001) Intracerebroventricular injection of pipecolic acid inhibits food intake and induces sleeping-like behaviors in the neonatal chick. Neurosci. Lett., 310: 97-100.

Teske, J.A., Levine, A.S., Kuskowski, M., Levine, J.A., Kotz, C.M. (2006) Elevated 
hypothalamic orexin signaling, sensitivity to orexin-A, and spontaneous physical activity in obesity-resistant rats. Am. J. Physiol., Regul. Integr. Comp. Physiol., 291: 889-899.

Tsujino, N., Sakurai, T. (2009) Orexin/Hypocretin: a neuropeptide at the interface of sleep, energy homeostasis, and reward system. Pharmacol. Rev., 61: 162-176.

Willie, J.T., Chemelli, R.M., Sinton, C.M., Yanagisawa, M. (2001) To eat or to sleep? Orexin in the regulation of feeding and wakefulness. Ann. Rev. Neurosci., 24: 429-458.

Yamanaka, A., Kunii, K., Nambu, T., Tsujino, N., Sakai, A., Matsuzaki, I., Miwa, Y., Sakurai, T. (2000) Orexin-induces food intake involves neuropeptide Y pathway. Brain Res., 859: 404-409.

Yamanaka, A., Beuckmann, C.T., Willie, J.T., Hara, J., Tsujino, N., Meida, M., Tominaga, M., Yagami, K., Sugiyama, F., Goto, K., Yanagisawa, M., Sakurai, T. (2003) Hypothalamic orexin neurons regulate arousal according to energy balance in mice. Neuron, 38: 701-713.

Yamamoto, Y., Ueta, Y., Yamashita, H., Asayama, K., Shirahata, A. (2002) Expressions of the prepro-orexin and orexin type 2 receptor genes in obese rat. Peptides, 23: 1689-1696.

Yuan, L., Ni, Y., Barth, S., Wang, Y., Grossman, R., Zhao, R. (2009) Layer and broiler chicks exhibit similar hypothalamic expression of orexinergic neuropeptides but distinct expression of genes related to energy homeostasis and obesity. Brain Res., 1273: $18-28$.

Zhao, R., Muehlbauer, E., Decuypere, E., Grossmann, R. (2004) Effect of genotype-nutrition on growth and somatotropic gene expression in the chicken. Gen. Comp. Endocrinol., 136: 2-11. 
Table 1. Effect of intracerebroventricular injection of orexin-A to layer chicks on feeding and arousal behavior for 1 hour after administration

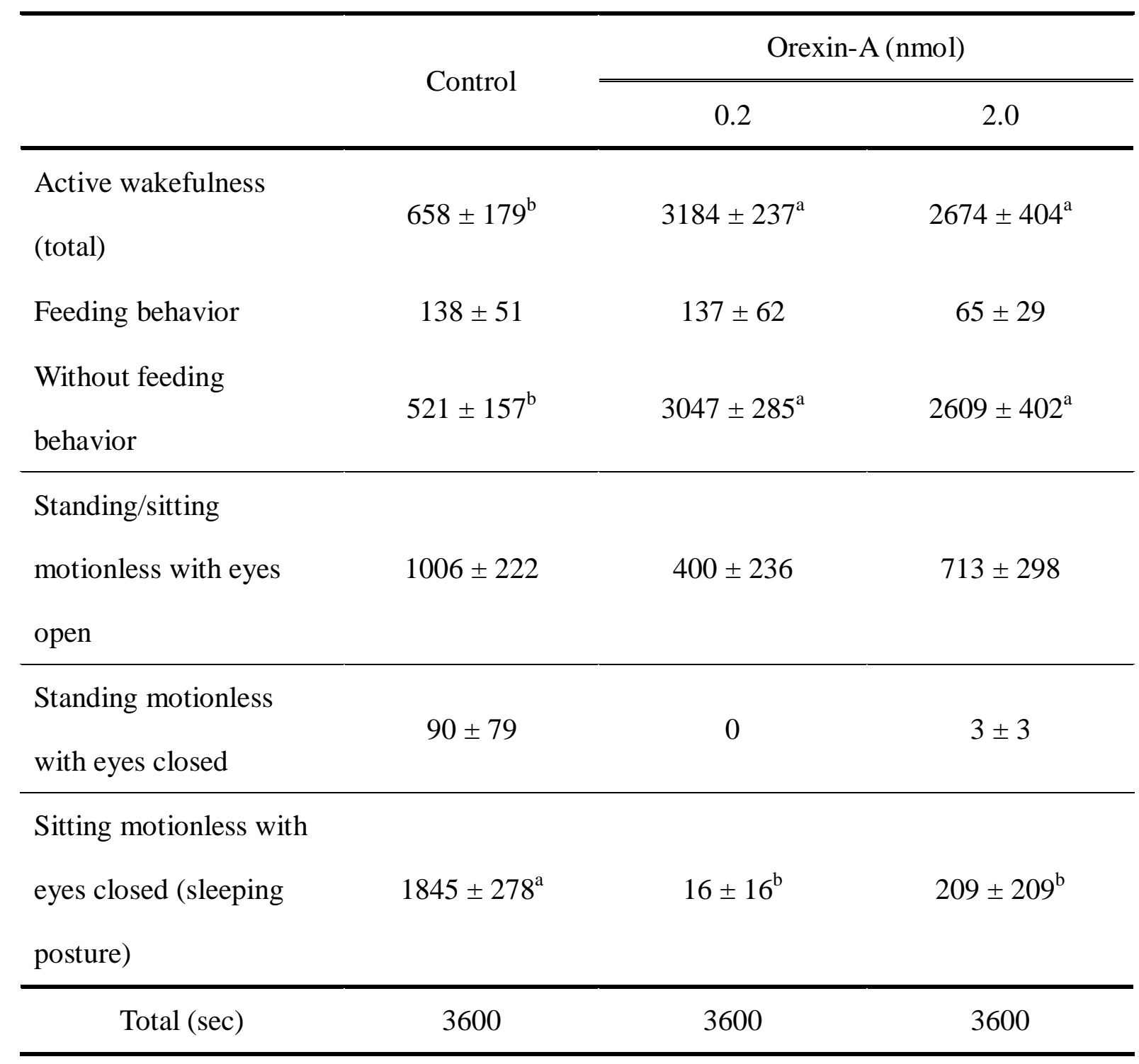

Values in second are means \pm S.E.M.

The number of chicks were control (vehicle): 7, orexin A 0.2 nmol: 6, 2.0 nmol: 8 .

${ }^{a, b}$ Values with a different superscript differs at $p<0.05$. 
Table 2. Behavioral observation for 1 hour after intracerebroventricular injection of orexin-B to layer chicks

\begin{tabular}{|c|c|c|c|}
\hline & \multirow{2}{*}{ Control } & \multicolumn{2}{|c|}{ Orexin-B (nmol) } \\
\hline & & 0.2 & 2.0 \\
\hline $\begin{array}{l}\text { Active wakefulness } \\
\text { (total) }\end{array}$ & $2287 \pm 350$ & $2002 \pm 496$ & $2507 \pm 461$ \\
\hline Feeding behavior & $247 \pm 91$ & $126 \pm 71$ & $52 \pm 22$ \\
\hline $\begin{array}{l}\text { Without feeding } \\
\text { behavior }\end{array}$ & $2040 \pm 326$ & $1877 \pm 463$ & $2456 \pm 468$ \\
\hline $\begin{array}{l}\text { Standing/sitting with } \\
\text { eyes open }\end{array}$ & $697 \pm 97$ & $1515 \pm 460$ & $1093 \pm 461$ \\
\hline $\begin{array}{l}\text { Standing with eyes } \\
\text { closed }\end{array}$ & $15 \pm 12$ & $19 \pm 14$ & 0 \\
\hline $\begin{array}{l}\text { Sitting with eyes } \\
\text { closed } \\
\text { (sleeping posture) }\end{array}$ & $601 \pm 272$ & $63 \pm 46$ & 0 \\
\hline Total (sec) & 3600 & 3600 & 3600 \\
\hline
\end{tabular}

Values in second are means \pm S.E.M.

The number of chicks were control (vehicle) : 9, orexin A 0.2 nmol: 5, 2.0 nmol: 6 . 
Table 3. Behavioral observation for 1 hour after intracerebroventricular injection of orexin-A to broiler chicks

\begin{tabular}{|c|c|c|c|}
\hline & \multirow{2}{*}{ Control } & \multicolumn{2}{|c|}{ Orexin-A (nmol) } \\
\hline & & 0.2 & 2.0 \\
\hline $\begin{array}{l}\text { Active wakefulness } \\
\text { (total) }\end{array}$ & $2139 \pm 251$ & $2341 \pm 304$ & $2213 \pm 438$ \\
\hline Feeding behavior & $401 \pm 58^{\mathrm{b}}$ & $175 \pm 39^{\mathrm{a}}$ & $103 \pm 27^{\mathrm{a}}$ \\
\hline $\begin{array}{l}\text { Without feeding } \\
\text { behavior }\end{array}$ & $1738 \pm 231$ & $2166 \pm 289$ & $2109 \pm 432$ \\
\hline $\begin{array}{l}\text { Standing/sitting with } \\
\text { eyes open }\end{array}$ & $1030 \pm 190$ & $1079 \pm 238$ & $1234 \pm 358$ \\
\hline $\begin{array}{l}\text { Standing with eyes } \\
\text { closed }\end{array}$ & $3 \pm 3$ & 0 & 0 \\
\hline $\begin{array}{l}\text { Sitting with eyes } \\
\text { closed } \\
\text { (sleeping posture) }\end{array}$ & $426 \pm 245$ & $180 \pm 109$ & $154 \pm 91$ \\
\hline Total (sec) & 3600 & 3600 & 3600 \\
\hline
\end{tabular}

Values in second are means \pm S.E.M.

The number of chicks were control (vehicle): 7, orexin A 0.2 nmol: 7, 2.0 nmol: 8 .

${ }^{a, b}$ Values with a different superscript differs at $\mathrm{p}<0.05$. 
Table 4. Behavioral observation for 1 hour after intracerebroventricular injection of orexin-B to broiler chicks

\begin{tabular}{|c|c|c|c|}
\hline & \multirow{2}{*}{ Control } & \multicolumn{2}{|c|}{ Orexin-B (nmol) } \\
\hline & & 0.2 & 2.0 \\
\hline $\begin{array}{l}\text { Active wakefulness } \\
\text { (total) }\end{array}$ & $1424 \pm 499$ & $2417 \pm 373$ & $2073 \pm 475$ \\
\hline Feeding behavior & $207 \pm 89$ & $159 \pm 79$ & $80 \pm 43$ \\
\hline $\begin{array}{l}\text { Without feeding } \\
\text { behavior }\end{array}$ & $1217 \pm 513$ & $2258 \pm 359$ & $1994 \pm 457$ \\
\hline $\begin{array}{l}\text { Standing/sitting with } \\
\text { eyes open }\end{array}$ & $677 \pm 162$ & $694 \pm 126$ & $1036 \pm 353$ \\
\hline $\begin{array}{l}\text { Standing with eyes } \\
\text { closed }\end{array}$ & $2 \pm 2$ & 0 & 0 \\
\hline $\begin{array}{l}\text { Sitting with eyes closed } \\
\text { (sleeping posture) }\end{array}$ & $1498 \pm 503$ & $486 \pm 330$ & $490 \pm 282$ \\
\hline Total (sec) & 3600 & 3600 & 3600 \\
\hline
\end{tabular}

Values in second are means \pm S.E.M.

The number of chicks were control (vehicle): 6, orexin A 0.2 nmol: 7, 2.0 nmol: 7 . 